УДК $81 ` 43$

ББК 81.1

DOI: https://doi.org/10.17308/lic.2020.1/2736

\title{
АНГЛОЯЗЫЧНЫЕ ЮРИДИЧЕСКИЕ МАРКЕТПЛЕЙСЫ КАК ПРОСТРАНСТВО ФУНКЦИОНИРОВАНИЯ ПОПУЛЯРНОГО ЮРИДИЧЕСКОГО ДИСКУРСА (НА МАТЕРИАЛЕ ТЕКСТОВ О БАНКРОТСТВЕ ФИЗИЧЕСКИХ ЛИЦ США)
}

\author{
А. С. Аверин
}

Воронежский государственный университет

\author{
ENGLISH-LANGUAGE MARKETPLACES AS THE FIELD \\ OF POPULAR LEGAL DISCOURSE \\ (ON THE MATERIAL OF THE USA BANKRUPTSY LAW)
}

\author{
A. S. Averin \\ Voronezh State University
}

\begin{abstract}
Аннотация: в статье рассматривается такое современное англоязычное пространство развертывания популярно-юридического дискурса, как правовые сайты -маркетплейсы, а также анализируется специфика текстов, содержащихся на таких интернет-ресурсах. Объем онлайн-коммуникации, в том числе по правовым вопросам, постоянно растет, что требует внимания со стороны ученых-лингвистов. Целью исследования является установление языковой специфики текстов с англоязычных сайтов - маркетплейсов, а также выявление характера данного дискурса. Использованы методы анализа, синтеза, сопоставительный, конструктивный, дистрибутивный. Автор проводит типологию западных юридических сайтов на основе характера коммуникации между авторами текстов и их адресатами. Одним из типов таких интернет-ресурсов являются маркетплейсы. Рассматриваются их примеры и специифика с позиции лингвистических особенностей содержашихся там текстов. Также проанализированы некоторые аспекты темы, связанные с удобством поиска нужных текстов на конкретных сайтах (интерфейс и рубрикация). Отмечены некоторые недостатки структурирования корпуса текстов на некоторых сайтах, что делает поиск нужной информации более длительным. В ходе работы было исследовано 30 текстов с 3 сайтов. В статье приводятся примеры некоторых из них с детальным разбором языковых особенностей и назначения. Автор фиксирует ряд признаков, позволяющих однозначно отнести рассмотренные тексты именно к популярно-юридическому дискурсу. Обращается внимание на практическую полезность и физическую и смысловую доступность таких текстов для пользователей Интернета. Также отмечается определенный уровень коммерциализации проиесса коммуникации в рамках изучаемых сайтов. Результаты работы могут быть использованы при написании популярно-юридических текстов, создании тематических сайтов и в дальнейших разработках по данному вопросу. Сделаны выводы об удобстве коммуникации юристов и людей, не обладающих правовыми знаниями посредством сайтов -маркетплейсов, о специфике такого дискурса, а также перспективах дальнейших исследований в данном направлении. Ключевые слова: юридический дискурс, популярный юридический дискурс, коммуникаиия, Интернет, дискурсология.
\end{abstract}

Abstract: the author studies a contemporary English-language field of popular legal discourse called marketplace websites. He also analyzes the features of the texts from such sources. The websites are classified by the type of communication between the texts 'authors and readers. A number of legal marketplace websites are analyzed from the point of it's textual content. The purpose of the research is to study legal marketplace websites and their texts and outline the features of such websites discourse. In the course of the research different methods were used

(C) Аверин А. С., 2020

Контент доступен под лицензией Creative Commons Attribution 4.0 License.

The content is available under Creative Commons Attribution 4.0 License. 
such as analysis and synthesis, comparative method, constructive and distributive methods. The author also paid attention to the convenience of searching for the necessary legal texts within the websites. Some of the sites are not effective from the point of arranging the texts by topic, subtopic and areas of law. This makes finding the required information and communicating more difficult. Fifty texts from three websites were analyzed in the course of the research. Several texts are examined in this article to illustrate the purposes and language features of the texts. The author describes a number of characteristics which give the texts a special discursive character. Marketplace websites contain texts which are useful and accessible for internet users. A particular level of commercialization of such discourse was discovered. The results of the research can be applied in the course of writing popular legal texts, arranging websites content and conducting other research. The author made a number of conclusions about convenience of communication between lawyers and lay people via marketplace websites and also about it's specific discourse.

Key words: legal discourse, popular legal discourse, communication, internet, discourse studies.

В одном из выступлений основатель компании Amazon Джефф Безос рассказал о начале своей карьеры. По его словам, в 1996 г. и в последующие несколько лет Интернет в США и западных странах лишь начинал развиваться, но этот процесс шел фантастическими темпами - минимум 200 \% в год. Инвесторы, соглашавшиеся с ним работать, первым делом задавали один и тот же вопрос: «Что такое Интернет?». Однако уже через 10 лет многие граждане западных стран думали над другими вопросами: как они жили без Интернета раньше; как жить, если его не будет. Сегодня миллиарды людей на всей планете воспринимают всемирную сеть как некую вторую реальность, параллельную социальной и физической. Такой масштабный и глубокий сдвиг социальной и ментальной реальности должен всесторонне изучаться всеми науками, так или иначе связанными с обществом, человеком и коммуникацией. Лингвистика - не исключение. Социальные контакты любого характера получают некий цифровой аналог в сети Интернет, который как минимум дублирует традиционное общение лицом к лицу (а как максимум заменяет и вытесняет его). Процесс, затрагивающий всю систему, не может не менять ее отдельные элементы. Речь идет о взаимодействии индивидов по поводу разрешения юридических вопросов. На момент окончания второго десятилетия XXI в. коммуникация между профессиональными юристами и их клиентами все чаще осуществляется в сети Интернет. В 2017 г. Mark A. Cohen в статье «It's Time For A Digital Legal Marketplace» писал: «A new digital marketplace is also emerging. It is changing the way legal services are bought and sold» [1]. Незаметно для многих выросла целая индустрия онлайн-юриспруденции. Данное утверждение особенно актуально для англоязычного Интернета, где крупные правовые порталы ежедневно посещают тысячи пользователей. Основной продукт таких сайтов - информация, организованная в формате разъяснительных текстов по правовым темам. Сегодня научный анализ англоязычных популярных правовых текстов должен ориентироваться на онлайн-дискурс как равнозначный более привыч- ным и традиционным (например, газетному, телевизионному дискурсам).

В качестве материала исследования использованы тексты с трех наиболее посещаемых сайтов - маркетплейсов по юридической тематике. Также были проанализированы некоторые посещаемые англоязычные сайты, содержащие популярно-юридические тексты, но не относящиеся к маркетплейсам. Всего было проанализировано 30 текстов по вопросу банкротства физических лиц в США. В настоящей статье приведены в качестве примеров и проанализированы несколько наиболее типичных из них с целью максимально наглядно проиллюстрировать специфику изучаемого дискурса.

В ходе работы с материалом использовались общенаучные и частнонаучные методы. К первым относятся анализ и синтез. Метод анализа применялся для детального изучения образцов материала (текстов подлежавшего рассмотрению дискурса). С помощью синтеза делались выводы о сходствах, различиях и особенностях тех или иных составных элементов материала. Из числа частнонаучных методов использовались сопоставительный, конструктивный, дистрибутивный.

Начнем более подробное рассмотрение темы с анализа англоязычных сайтов, содержащих популярные тексты по правовой тематике. Проведенное исследование показало, что можно говорить как минимум о двух типах онлайн-платформ. В качестве основания деления выступает критерий характера коммуникации между автором дискурса (общедоступного текста на сайте) и его конечными адресатами. В первом случае создатель текста порождает дискурс по определенной теме, не отвечая конкретному субъекту на конкретный вопрос. Во втором случае речь идет о разъяснении конкретной ситуации, которое будет полезно для широкого круга лиц.

Первый тип: информационные сайты, на которых размещены разъяснительные юридические тексты, не отвечающие на конкретный вопрос конкретного пользователя. Такие тексты можно условно назвать статьями разъяснительного характера (наподо- 
бие газетных). Рассматриваемые сайты, как правило, имеют тематические разделы в соответствии с отраслями права и видами правоотношений. Один из примеров таких сайтов - Justia.com [2]. На нем не предоставляются тексты консультационного характера в качестве ответов на каждый заданный клиентами вопрос. По объему и разнообразию разделов данный сайт может быть назван интернет-порталом. Посетитель выбирает категорию пользователя и получает доступ к каталогу необходимой информации соответствующего уровня сложности и детализации. На первой странице сайта можно выбрать информационные блоки «Для бизнеса», «Для студентов-юристов», «Для физических лиц», «Найти юриста» и др. Выбираем заголовок «Для физических лиц» (“Individuals”). Информация в пределах данной части сайта организована по основным отраслям права. Выбираем «Банкротство», находим нужный заголовок с тематикой проблемы (например, «Альтернативы банкротству»). Страница начинается с разъяснительного текста о банкротстве в целом, содержащего информацию по следующим вопросам:

- в чем суть банкротства физического лица и когда его можно применять;

- какие результаты может принести банкротство;

- чем отличаются разные виды банкротства физических лиц;

- каковы альтернативы банкротству.

Далее можно выбрать более узкие темы. Например, банкротство по ст. 7, банкротство по ст. 13 и т. д. (что именно имеется в виду, авторы и администрация сайта не уточняют). Все тексты, содержащиеся в указанных разделах, не являются ответами на конкретные вопросы определенного пользователя. Они в целом разъясняют тематику правоотношений, связанных с банкротством. Данный сайт может характеризоваться как один из наиболее удобных с точки зрения поиска необходимой информации. Особенно эффективно структурирование материалов по принципу субъекта поиска (например, «Law students», «Business», «Individuals» и др.).

Рассмотрим еще один пример сайта первого типа (Freeadvice.com) [3]. В поисковой системе Google он предлагается в качестве первого поискового результата по запросу «free legal advice». На главной странице сайта располагается заголовок «Helping 20 Million Americans a Year for 20 Years. FREE!». Также на первой странице предлагается заполнить форму вопроса юристу. Ниже приводятся категории, соответствующие наиболее актуальным в практическом смысле отраслям и подотраслям права. При выборе одной из них пользователь переходит на страницу, где перечисляются подотрасли в рамках выбранной отрасли. Для примера выбираем Bankruptcy и переходим на страницу с более узкими темами (Business
Bankruptcy, Consumer Bankruptcy, Credit Problems и др.) и выбираем рубрику Consumer bankruptcy (Банкротство потребителя) [4]. Открывшаяся страница еще более детально рубрицирует вопросы в рамках избранной тематики. Например, виды банкротства, процедуры банкротства, банкротство и кредит. Выбираем рубрику Bankruptcy Procedure, переходим на страницу, где приводится еще более детальный список вопросов по тематике "What is involved in the bankruptcy process». Например, «The Bankruptcy Means test». Таким образом, данный сайт предлагает посетителю четыре уровня конкретизации тематики его вопросов, что упрощает поиск нужных ответов и позволяет представить и осознать всю картину правовой системы в целом. На сайте FreeAdvice.com не указывается, какой юрист отвечал на конкретный вопрос, не приводятся его имя, фамилия, фотография. Также нет возможности вступить с ним в переписку для дальнейшего сотрудничества (найма в качестве представителя в суде, например). Приводится лишь общая фраза перед текстом каждого вопроса на сайте: «By Free Advice staff». Это все, что можно узнать об авторе ответа. Недостаточно продуманное структурирование и рубрикация корпуса текстов конкретного сайта является существенным препятствием для правовой коммуникации его пользователей. Поиск нужного текста осуществляется лицами, не имеющими профессиональных юридических знаний. В силу этого они могут испытывать затруднения в отнесении интересующего их вопроса к той или иной рубрике, теме (отрасли права, подотрасли права).

Второй тип юридических сайтов с разъяснительными (популярными) текстами можно условно назвать онлайн-приемными, где профессиональные юристы консультируют всех желающих на безвозмездной основе. Как правило, сайты рассматриваемого типа реализованы в формате маркетплейса. Что имеется в виду? Технический директор IT-компании «Lodoss» A. Репьёв определяет маркетплейсы как «торговые интернет-площадки, которые выступают посредником между покупателем и продавцом» [5]. Самые известные примеры маркетплейсов Aliexpress, «Ваш репетитор», «Яндекс-маркет» (с 2019 г. называется «Беру»). В нашем случае речь идет о маркетплейсах услуг. Создатели таких сайтов не являются профессиональными юристами и не имеют отношения ни к специалистам, консультирующим на их сайте, ни к посетителям, задающим вопросы. Юристы регистрируются на сайте и дают ответы в надежде привлечь потенциального клиента, а посетители получают бесплатную письменную консультацию и возможность выбора специалиста. Как показал проведенный анализ, на большинство вопросов отвечает несколько юристов. Соответственно, созданные ими правовые тексты различаются по содержа- 
нию, глубине рассмотрения проблемы, стилю, объему. Все это определенным образом характеризует конкретного специалиста в глазах клиента. Как известно, речь выступает одним из факторов идентификации человека как своего или чужого. Именно поэтому критерием для выбора клиентом своего будущего адвоката может выступать не только и не столько профессионализм, продемонстрированный в ответе. Важную роль может сыграть стиль изложения правовой информации. Имеется в виду степень понятности и неформальности изложения, обращение и отношение юриста к автору вопроса. Существенное значение может иметь оперативность ответа на вопрос, наличие или отсутствие фотографии юриста и другие факторы. Итак, сущностным признаком юридического маркетплейса является порядок создания разъяснительного дискурса: на вопрос конкретного пользователя отвечают практикующие юристы, стремящиеся привлечь клиентов. При этом администрация сайта является по отношению к их коммуникации третьей стороной, никак в ней не участвуя. Примеры таких сайтов: avvo.com, HG.org. Рассмотрим один из самых популярных юридических ресурсов англоязычного Интернета HG.org [6]. На главной странице сразу бросается в глаза небольшой рекламный баннер, содержащий заявление «Need a lawyer? Let HG.org help you today?» («Нужен юрист? Сайт HG.org поможет вам прямо сейчас»). Там же предлагается найти юриста в соответствующем Штате США по необходимой сфере права. В верхней части страницы выбираем пункт меню «Legal articles». В рубрике «Банкротство» выбираем «Debt relief». Кликаем название рубрики и переходим к списку статей (которые никак не упорядочены). После названия каждой статьи приводятся первые слова текста и ссылка на страницу юридической фирмы, предоставившей текст. Выбираем одну из приведенных в начале ссылок: «3 misconceptions around bankruptcy» [7]. Данная статья является ответом на вопрос конкретного юриста конкретному пользователю. В конце текста указывается компания, где работает автор статьи Eric Reed, а также его контакты (телефон, сайт). При этом по сравнению с другими ресурсами аналогичной тематики рубрикация статей на сайте HG.org достаточно поверхностная и не слишком удобная. Строго говоря, речь идет лишь об одном уровне рубрицирования - делении статей по отраслям права (семейное право, уголовное право, трудовое право и т. д.). Если открыть общую страницу со всеми материалами по тематике «банкротство», можно увидеть список почти из 500 статей, которые никак не систематизированы. Причем не указано, о каком именно банкротстве идет речь - физического или юридического лица (что имеет первостепенное значение при выборе материалов пользователями). Итак, рассмотренный сайт
HG.org имеет все признаки юридического маркетплейса:

- администрация сайта предоставляет площадку коммуникации юристов и пользователей (потенциальных клиентов), не являясь участником такого взаимодействия;

- авторы ответов на вопросы и разъяснительных текстов - профессиональные юристы, заинтересованные в качественной консультационной помощи пользователям сайта для дальнейшего привлечения клиентов и продвижения бренда компании или пиара себя как специалиста;

- адресаты дискурса - индивиды, нуждающиеся в безвозмездном получении знаний юридического характера по интересующим их практическим ситуациям.

Перед рассмотрением конкретных текстов обратимся к содержанию понятия популярный юридический дискурс. Считаем возможным также называть его популярно-юридический дискурс, популярный правовой дискурс, популярно-правовой дискурс. На наш взгляд, реальных смысловых изменений при перемене слова «юридический» на «правовой» не происходит, равно как и при вариациях «популярно-юридический» и «популярный юридический». В науке юридический дискурс определяется по-разному. Многие дефиниции выглядят и звучат объемно и масштабно (например: «мы рассматриваем юридический дискурс как особый тип институционального дискурса, семиотическое пространство которого характеризуется совокупностью вербальных и невербальных знаков (и их вербальных коррелятов), формирующих как институциональные, так и неинституциональные формы общения, в которых субъект, адресат или содержание (или хотя бы одна их этих составляющих) имеют отношение к сфере юриспруденции и/или встречаются в рамках пересечения данного дискурса с другими типами дискурса (исторического, политического, педагогического, военного, дискурсом СМИ, художественным дискурсом и др.)» [8]. Очевидно, что если к такому определению добавить еще и смысловой элемент, отвечающий за популярный характер юридического дискурса, определение станет слишком громоздким. Поэтому ограничимся лишь описанием основных сущностных элементов, образующих указанное понятие.

1. Предмет коммуникации (вопросы юридического характера).

2. Цель взаимодействия (разъяснить профессиональные правовые вопросы лицам, не обладающим соответствующими познаниями).

3. Ряд типичных языковых характеристик (отсутствие канцеляризмов, профессиональных терминов и т. д.). 
Перейдем к рассмотрению ряда примеров разъяснительных (популярных) юридических текстов, содержащихся на юридических маркетплейсах. Типичным образцом искомых интернет-ресурсов является названный выше HG.org. Нами были выбраны для исследования 30 статей. Каждая из них начинается с краткого вступления, описывающего содержание текста в одном-двух предложениях. Справа от вводной части каждой статьи располагается фотография - логотип юридической фирмы, чьи сотрудники являются авторами текста. После текста приводится адрес сайта фирмы, контактный телефон, имя и фамилия автора, а также заявление об отказе от ответственности (Disclaimer). Приведем текст данного примечания сразу на русском языке в переводе автора настоящей работы: «Отказ от ответственности: несмотря на то, что были приложены все усилия для обеспечения точности данного текста, он не носит характер юридической консультации, поскольку конкретные практические ситуации различны и должны обсуждаться с экспертом и/или юристом. Для получения конкретных технических или юридических консультаций по предоставленной информации и смежным темам, пожалуйста, свяжитесь с автором». С одной стороны, такое примечание является защитой от потенциальных исков тех, кто может подать в суд на автора в случае неудачных юридических действий на основе данной статьи. С другой - посетителю сайта лишний раз напоминают, что заменить дорогостоящие услуги юриста изучением популярно-юридических статей не получится. В отличие от многих аналогичных сайтов, на данном интернет-ресурсе не приводятся фотографии или личные контактные данные авторов статей, а также отзывы об их работе или сведения о штате, в котором они практикуют. В целом можно говорить о том, что метатекст публикаций на данном сайте ориентирует посетителя на восприятие разъяснительного дискурса как первого шага к найму юриста. Тексты скорее позволяют понять правовые аспекты ситуации, в которой оказался пользователь, сформировать общее осознание происходящего с юридической точки зрения, составить первичный план действий, наметить первые шаги по решению проблемы. Однако при необходимости и наличии времени и целеустремленности с помощью подобных статей и сайтов можно выстроить полноценную линию защиты, представлять свои интересы в суде и без опыта юридической работы. Рассмотрим для примера уже упоминавшийся выше разъяснительный текст «3 Misconceptions Around Bankruptcy» («3 заблуждения, связанных с банкротством»). Текст написан достаточно простым и доступным для понимания языком, но при этом отсутствуют жаргонизмы, просторечные выражения и в целом выдержан официально-деловой стиль («Bankruptcy protection can help those who are struggling with debt come out on the other side»). Сложные профессиональные термины заменены объяснениями их содержания («Although bankruptcy is a matter of public record, it's unlikely that your family, friends and neighbors will access the news. Unlike foreclosures, your local paper will not announce your bankruptcy» - «Хотя банкротство является публичным процессом, маловероятно, что ваша семья, друзья и соседи получат доступ к информации о вашем деле. В отличие от продажи находящегося в ипотечном залоге дома, ваша местная газета не будет объявлять о вашем банкротстве»). Для удобства понимания использованы вводные слова, передающие логику закона и рассуждений автора («...although bankruptcy is a matter of public record...»- - здесь и далее в цитатах-примерах курсив наш. $-A$. $A$.). Текст несовершенен с точки зрения некоторых лингвистических параметров (сказывается то, что он написан юристами, а не профессионалами в сфере создания дискурса - филологами, журналистами). Например, имеют место тавтологии («Although bankruptcy is a matter of public record, it's unlikely that your family, friends and neighbors will access the news. Unlike foreclosures, your local paper will not announce your bankruptcy»). В исследуемом тексте встречаются фразы, направленные не просто на объяснение, но и на успокоение и моральную поддержку людей, попавших в сложную финансовую ситуацию. Например: «If you file for Chapter 13 bankruptcy, you'll learn to adopt positive money management habits. This is because Chapter 13 bankruptcy requires the person who files to repay their debts over a period of three to five years. With these skills in your back pocket, you're likely to handle your finances responsibly as time goes on» («Если вы подадите заявление о банкротстве в порядке главы 13, вы научитесь полезным привычкам управления капиталом. Это связано с тем, что при банкротстве в соответствии с главой 13 лицо, которое подает документы, должно погасить свои долги в течение трех-пяти лет. Обладая этими навыками, вы, скорее всего, будете ответственно обращаться со своими финансами»). Отметим, что данный текст является одним из наиболее грамотно написанных, полезных и эффективных из всех проанализированных как на сайте HG.org, так и на других интернет-площадках.

Рассмотрим еще один текст из раздела «Банкротство» - «Chapter 7 Bankruptcy Could Alleviate Medical Debt» («Банкротство физического лица по процедуре главы 7 может уменьшить долги по медицинскому обслуживанию») [9]. Достаточно эффективно разъяснена выгодность процедуры банкротства по главе 7: «Chapter 7 bankruptcy makes it possible for debtors to have a significant amount of their debts discharged. It is possible to have medical debts discharged in Chapter 7 bankruptcy, provided that you meet the criteria for filing» 
(«Банкротство по процедуре главы 7 позволяет должникам погасить значительную сумму своих долгов. Возможно погашение задолженности по медицинским расходам при банкротстве по главе 7, при условии, что вы соответствуете критериям для подачи заявки»). Существенный недостаток анализируемого текста, равно как и многих других в разделе «Банкротство» - не объясняется значение фраз «Chapter 7 bankruptcy» и «Chapter 13 bankruptcy». Для человека, не обладающего юридическими познаниями, не понятно даже само подразделение института банкротства физического лица на 2 вида: по главе 7 и по главе 13, не говоря уже о содержательных отличиях этих процедур. Вернемся к анализу текста. Существенно упрощает восприятие наводящий вопрос, служащий в структуре текста в качестве подзаголовка смысловой части: «What Are the Criteria for Making a Chapter 7 Bankruptsy Filing?». Далее разъясняются критерии, которым должен соответствовать гражданин, желающий пройти через процедуру признания банкротом. Снова встречаем тавтологию, которая, однако, заставляет воспринимать предложения как предельно простые для понимания: «In order to file, you must pass a means test. This means test is based on your household income and outgoings». Далее приводятся варианты развития событий, альтернативные банкротству по главе 7: «There are several options available to you if you are struggling with overwhelming medical debt. You may be able to negotiate with creditors or modify repayment plans» («Есть несколько вариантов, доступных для вас при невозможности выплачивать долги по медицинскому обслуживанию. Вы можете договориться с кредиторами или изменить план погашения долга»). Предложение построено блестяще с позиции его разъяснительной направленности. С одной стороны, сложный аспект избежания процедуры банкротства изложен доступным языком, с другой - ничего не упущено и смысл передан полностью. Статья завершается предложением «However, if you decide that Chapter 7 bankruptcy could be the best option for you, it is important to prepare sufficiently and plan ahead» («Однако если вы решите, что банкротство по главе 7 может быть лучшим вариантом для вас, важно серьезно подготовиться и подготовить план заранее»). Вводное слово however облегчает восприятие с точки зрения логики изложения материала, а смысловая структура предложения дает понять, что «все только начинается»: если вы подходите для подачи заявления на банкротство по главе 7, это лишь первый шаг. Далее предстоит серьезная работа по подготовке к оформлению и подаче документов. Здесь также можно усмотреть скрытое побуждение к найму юриста. Однако до открытого рекламирования дело не доходит. В ходе исследований различных категорий популярно-юридических тек- стов мы неоднократно сталкивались с прямым склонением читателя к найму юриста - автора ответа на вопрос. Такие тексты не запрещены и они не теряют своей разьяснительной направленности, но, на наш взгляд, прямая реклама в разъяснительной статье своих услуг не идет автору на пользу, равно как и не улучшает сам текст (который является ни чем иным как письменной консультацией по правовому вопросу). Можно говорить о том, что рассмотренные тексты достаточно эффективны с точки зрения первичной правовой помощи лицам, не обладающим юридическими познаниями и стремящимся понять ситуацию, в которой они оказались и выходы из нее. Итак, плюсы онлайн-консультирования по юридическим вопросам (для клиента) очевидны. Приведем их список.

1. Консультация бесплатна.

2. Не нужно тратить время и деньги, чтобы доехать до офиса специалиста.

3. Можно быстро без затрат и усилий получить мнения и консультации нескольких специалистов по своему вопросу.

4. Удобно сравнивать разных юристов в деле.

5. Ответ дается в письменном виде, хранится на сайте, он доступен и сегодня, и через неделю, и через год. Его невозможно забыть либо неправильно истолковать.

6. Практически полная анонимность.

Далее рассмотрим достоинства такой платформы коммуникации, как юридические маркетплейсы для профессиональных юристов.

1. Можно проводить консультирование в любое время и находясь в любом месте. Нужен только компьютер и Интернет.

2. Клиенты фактически сами находят специалиста.

3. Объяснение в письменном виде более эффективно и и доступно для восприятия.

Такой формат коммуникации, как юридический сайт - маркетплейс, становится все более популярным и эффективным средством взаимодействия между профессиональными юристами и лицами, не имеющими правовых знаний. Такие сайты позволяют эффективно и массово продуцировать, распространять и сохранять тексты популярного юридического дискурса. При этом указанные тексты характеризуются рядом специфических особенностей и носят ярко выраженный разъяснительный (популярный) характер, благодаря чему они достаточно эффективны для решения задачи коммуникации в рамках рассматриваемых интернет-платформ. Тексты, содержащиеся на страницах таких сайтов, являются практически полезными для лиц, не обладающих юридическими знаниями и попавших в сложные правовые ситуации. Как минимум они эффективны в качестве первичной правовой помощи и могут сориентировать пользова- 
теля в отношении начальных шагов по решению проблемы. При этом такие тексты доступны широкому кругу лиц и в смысле физической возможности ознакомления, и в значении понятности и практической применимости. Однако многие сайты достаточно навязчиво рекламируют юридические услуги и превращают разъяснительные тексты в рекламно-побудительные. Также имеются проблемы со структурированием корпуса текстов многих интернет-порталов по темам, что затрудняет поиск нужной информации.

\section{ЛИТЕРАТУРА}

1. Cohen M. A. It's Time For ADigital Legal Marketplace // Forbes. 2017. 07.01. URL: https: //www.forbes. com/sites/ markcohen 1/2017/01/07/its-time-for-a-digital-legalmarketplace/\#5115e 2b91f3e

2. Justia.com. URL: https://www.justia.com

3. Freeadvice.com. URL: https://www.freeadvice.com/

4. Bankruptcy. URL: https://bankruptcy-law. freeadvice. com/bankruptcy-law/

5. Репьев А. Сколько стоит разработать маркетплейс, и каких ошибок важно избегать. URL: https:// www.cossa. $\mathrm{ru} /$ trends/225416/

6. HG.org. URL: HG.org

7. 3 misconceptions around bankruptcy. URL: https:// www.hg.org/legal-articles/3-misconceptions-aroundbankruptcy-51442

8. Косоногова $O . B$. Характеристики юридического дискурса : границы, содержание, параметры // Историческая и социально-образовательная мысль. Краснодар, 2015. T. 7. № 1. C. 61-68.

Воронежский государственный университет

Аверин А. С., соискатель кафедры перевода и профессиональной коммуникаиии

E-mail:aaa7355@rambler.ru

Поступила в редакичию 20 сентября 2019 г.

Принята к публикации 27 декабря 2019 г.

\section{Для циитирования:}

Аверин A. C. Англоязычные юридические маркетплейсы как пространство функционирования популярного юридического дискурса (на материале текстов о банкротстве физических лиц США) // Вестник Воронежского государственного университета. Серия: Лингвистика и межкультурная коммуникация. 2020. № 1 . C. 87-93. DOI: https://doi.org/10.17308/lic.2020.1/2736
9. Chapter 7. Bankruptcy Could Alleviate Medical Debt. URL: https://www.hg.org/legal-articles/chapter-7bankruptcy-could-alleviate-medical-debt-51444

\section{REFERENCES}

1. Mark A. Cohen. It's Time For A Digital Legal Marketplace. Forbes. 07.01.2017. Available at: https:/www. forbes.com/sites/markcohen1/2017/01/07/its-time-for-adigitallegalmarketplace/\#5115e2b91f3e

2. Justia.com. Available at: https://www.justia.com

3. Freeadvice.com. Available at: https://www.freeadvice.com/

4. Bankruptcy. Available at: https://bankruptcy-law. freeadvice.com/bankrup tcy-law/

5. Repiyov A. Skolko stoit razrabotat marketplace i kakih oshibok vazhno izbegat [How much does it cost to develop a marketplace and what mistakes to avoid]. 2018. 15. 08. Available at: https://www.cossa.ru/trends/225416/

6. HG.org. Available at: HG.org

7. 3 misconceptions around bankruptcy. Available at: https://www.hg.org/legal-articles/3-misconceptionsaround-bankruptcy-51442

8. Kosonogova O. V. Kharakteristiki juridicheskogo diskursa: granitsy, soderzhaniye i parametry [Legal discource characteristics: limits, content, parameters]. Krasnodar: Istorycheskaya i sotsyalno-obrazovatelnaya mysl. 2015. V. 7. No 1. P. 66.

9. Chapter 7. Bankruptcy Could Alleviate Medical Debt. Available at: https://www.hg.org/legal-articles/chapter-7-bankruptcy-could-alleviate-medical-debt-51444

Voronezh State University

Averin A. S., Post-graduate Student of the Translation and Professional Communication Department

E-mail:aaa7355@rambler.ru

Received: 20 September 2019

Accepted: 27 December 2019

\section{For citation:}

Averin A. S. English-language marketplaces as the field of popular legal discourse (on the material of the USA bankruptsy law). Proceedings of Voronezh State University. Series: Linguistics and Intercultural Communication. 2020. No. 1. Pp. 87-93. DOI: https://doi.org/10.17308/lic.2020.1/ 2736 